\title{
Child porn users \& risk for engaging in contact offenses: faulty data minimizes offender's risk \& puts more children at risk for sexual abuse
}

\begin{abstract}
There has been a lot of research suggesting that the child porn user presents with low risk for engaging in actual sexual contact with children. However, to date, there is no empirical evidence to support that claim. Most of the research based the "low risk" status on offender self-report of having no contact victims and/or on the offender having no criminal conviction for engaging in sexual contact with children. Professionals are making a significant public safety decision based on faulty evidence and without utilizing scientific procedures such as polygraph. Research on child porn users demonstrates that $50-85 \%$ admit to having undetected child victims, and the average number of undetected victims per offender was 8 . So again, why are professionals relying on self-report and lack of criminal conviction to determine that the child porn offender poses minimal if any risk for sexually abusing minors? In addition, the use of child porn/child porn related erotica victimizes children involved in the child porn industry. The increased demand for more child porn and ways to collect and engage in the use of child related erotica results in the need for more and more material, which further sexually abuses children.
\end{abstract}

Volume 8 Issue 2 - 2020

\author{
Scott A Johnson \\ Licensed Psychologist, Forensic Consultation, USA
}

Correspondence: Scott A Johnson, Licensed Psychologist, Forensic Consultation, USA,

Email scott@forensicconsultation.org

Received: April 07, 2020 | Published: April 29, 2020

\section{Definitions}

Child Porn will include any porn or erotica that depicts anyone under the age of 18 for any sex or sex related purpose. This includes any material that portrays or involves the child or adolescent engaged in any type of sexual act or if the material is used for sexual gratification.

Child Porn Offender defines the person who engages in the use of online and offline child porn. In the purest sense, this person has not engaged in solicitation with children online and does not have any known contact sexual offenses involving a child. Child porn and child erotica may include both clothed and unclothed minors and may involve minors posing or engaging in sexual activity alone or with others.

Erotica defines any material or item that serves a sexual purpose for a given person (e.g., objects, magazines, pornographic material (e.g., dvd's, pictures), children's underwear, pictures of children (regardless of whether fully clothed or not), fetish items, writings, drawings, sexual paraphernalia, vibrators, sex toys, handcuffs, dolls, roll playing). Erotica is not deviant if it involves an age appropriate and consenting partner. Erotica can add to the intimate experience of a person or couple. However, erotica becomes deviant when it involves non-age appropriate people, nonconsenting people, animals, or objects. Erotica becomes deviant and harmful when it behaviorally relates to a crime or other paraphilias (e.g., deviant sexual fantasies, preferences, behaviors. ${ }^{1-4}$

\section{Questions for discussion}

\section{On what basis is the low risk status of child porn users given?}

In most cases, this is based on two factors, the first being the lack of any criminal conviction for engaging in any sex related crimes against children (anyone under the age of 18). The second appears to be self-admission on the part of the offender. This appears to be an inadequate rationale for assessing child porn offenders as being at low risk for engaging in contact offenses against minors. How long has the offender engaged in the deviant and sexually exploitive behavior versus when they were caught or prosecuted needs to be assessed. They may not get caught for years after engaging in the sexual molestation of children or minors and it may well take many more years to catch them a second time. Without use of polygraph is appears grossly premature to label a child porn only user at "low" risk for engaging in contact offenses.

Law-enforcement agencies active in investigations of Internetrelated sex crimes committed against minors have reported the proportion of arrested offenders who both sexually victimized children and possessed child pornography was high, ranging from $35 \%$ to $51 \%$ when prior offenses also were counted. ${ }^{5}$ They found $40 \%$ of the cases involving child porn possession in the N-JOV Study involved dual offenses of child porn possession and child sexual victimization detected in the course of the same investigation. ${ }^{6}$ A number of studies indicate a strong correlation between child pornography offenses and contact sex offenses against children. The National Juvenile Online Victimization (NJOV) study revealed contact offenses in one of every six cases that began as a child pornography investigation with no prior knowledge by law enforcement of possible contact offenses by the target. ${ }^{7}$ While no study can quantify the risk that any given child pornography offender poses for future contact offenses against children, the significant correlation between child pornography offenses and contact offenses signals that the risk is present. Sex offenders who reinforce their sexually deviant and nonsexual violent motivations through repeated viewing of deviant porn and child porn are at higher risk for sexual reoffense and contact offenses. This is supported by general learning theory and the concept of habituation and is supported in the literature for sexual offense behavior. ${ }^{8-16}$ In fact, masturbating to erotica (anything that a person finds sexually 
arousing) that is in any way related to a deviant sexual attraction or sexual offense behavior should be banned by use and possession by the offender. The cognitive distortions (e.g., rationalizations and excuses) offenders use to maintain their deviant sexual arousal and deviant sexual behavior help maintain the problem and may serve as permission giving. ${ }^{17}$

In 2009, The Department's Child Exploitation and Obscenity Section (CEOS) helped organize a Global Symposium for Examining the Relationship Between Online and Offline Offenses and Preventing the Sexual Exploitation of Children. The symposium members concluded "...that there is sufficient evidence of a relationship between possession of child pornography and the commission of contact offenses against children to make it a cause of acute concern, and that the greater availability of child sexual exploitation materials has stimulated the demand and production of even more extreme, sadistic, and violent images of children and infants". ${ }^{18}$ The important conclusions of this study support the continued risk of the child porn user in engaging in contact sexu crimes against children.

One study found that in a third of the federally prosecuted child pornography cases contact offenses were discovered. ${ }^{18}$ In addition, the United States Postal Inspection Service (USPIS) data also support the correlation between child pornography offenders and contact offenders. They found that between 1997 and 2008, for those arrested for child porn offenses, $32 \%$ were found to have committed contact offenses against children - either through an admission by the offender, a prior criminal record for sexual molestation, evidence uncovered during the child pornography investigation, or the discovery of overt acts by the offender to procure children for sexual purposes U.S. Department of Justice, 2010, pp. $20 .{ }^{18}$ Several national child pornography operations uncovered several contact sex offenders among child porn offenders. ${ }^{18}$

The overall findings suggest that child porn offenders are more likely to have undetected contact victims. Self-report is not a valid not accurate means to determine the lack of any contact victims. Undetected child sexual abusers tended to be: ${ }^{19}$ 1) younger; 2) more educated; 3) employed; 4) less reported histories of childhood sexual abuse; and 5) presented with less socio-affective deficits which suggests less childhood maltreatment and more secure parent-child relationships. This suggests that the child porn user who has yet to be detected for engaging in contact sexual offenses is more capable to remain undetected. They tend to be smart, witty, they fit into society, and can easily con others. Therefore, not a low risk sex offender at all. Much like Sandusky.

\section{Is self-report on the part of a child porn user to be believed?}

The offender has many reasons not to self-admit actual sexual contact with a minor. Why not use polygraph before believing the offender's denial of having never engaged in contact sexual offenses. The offender's illegal behavior, which they managed for the most part to keep secretive, demonstrates that they are cunning and conning and very able to mislead. In addition, the vast majority of sexual offenses against children are vastly undetected and unreported. ${ }^{20}$ Referencing the Jerry Sandusky case, how many years did people make allegations that were dismissed without appropriate investigation or due to a lack of evidence or concerns about the credibility on the victim's part Many children will not report the abuse for several years, thereby making it less likely for the case to be prosecuted. So again, why do we rely on the offender's denial of contact offenses as somehow being factual or credible?
Approximately $20-25 \%$ of investigations for child porn crimes uncover undetected contact child sex crimes. ${ }^{6,21}$ Owens also found that $25 \%$ of child porn offenders had at least 1 victim, however, several had many victims. ${ }^{21}$ Others found that $26-85 \%$ of child porn offenders have multiple child contact victims that were previously undetected. ${ }^{22-25}$ The admissions of the child porn only offender that led to disclosure of previously undetected victims occurred either while in treatment and being asked specific questions about the presence of undetected victims and/or when polygraphed..$^{26}$ Polygraph offers the most reliable situation to determine the veracity of an offender's claim of having or not having contact or additional victims.

The literature supports that the child porn offender posses substantial risk for contact sexual offending, yet some of the literature minimizes this risk solely based on a short follow-up period (generally less than 3 years), offender self-report, the lack of any direct sex offense convictions, and few utilized polygraph exams. Regarding the significance of any criminal history, directly sexual in nature or not, it is important to never underestimate the significance of nuisance sex offenses as these offenses often are part of an offenders larger deviant scheme. ${ }^{25}$ Pay attention to any similarities between the nuisance offenses and actual sexual offense behavior. ${ }^{23}$ Many of the offenders may not have any criminal history or no criminal sexual offense history. This does not make the offender any less dangerous, it simply means they likely have never been arrested or detected in the past. Of those offenders who had no prior sex offense convictions but admitted having undetected contact victims, they had the most victims. ${ }^{21}$ Many of the child porn offenders with the most contact offenses went undetected at least in part to their not having a criminal history and skills at grooming. ${ }^{26} \mathrm{~A}$ high percentage of children sexually abused likely never report the sexual contact or may not do so until they are much older, reducing the likelihood of prosecution due to the time lapse. ${ }^{27}$ This is one factor that necessitates that recidivism and crossover data cover 10 or more years to assess for contact offense behavior. Child porn offenders admit to having on average 8-20 undetected victims of child sexual abuse, ${ }^{28}$ the overall results of their study indicated that as many as $85 \%$ had undetected victims.

Factors that suggest a child porn offender may be at high risk for contact offenses or may already have engaged in undetected contact offenses include any of the following:

- The offender has a prior history of sex offenses.

- The offender demonstrates a certain commitment to the collection or trade or both of child pornography.

- The offender has been involved in the collection or trade of child pornographic images for a relatively long time.

- The offender participates in online child pornography communities.

- The offender uses more than one technology to collect or trade child pornography.

- The offender uses advanced technologies to collect, or trade, or both, child pornography.

- The offender uses sophisticated technologies or practices to avoid detection.

- The offender shows an interest in images depicting extreme sexual conduct or very young victims. 
- The offender exhibits extreme care building, maintaining, and categorizing his collection of child pornography.

- The offender communicates with other offenders in online communities about his sexual interest in children.

The presence of any of these factors should alert law enforcement that the offender may well be a contact offender, especially if the offender has ready access to children. In many cases when law enforcement executes a search warrant for a computer and premises of an offender who appears to be only a child porn offender, evidence is discovered to prove that the offender is in fact a contact offender with undetected victims. For more risk factors and areas of concerns, see Johnson. ${ }^{4}$ Most sexual offenses against children are vastly undetected and unreported. ${ }^{20}$

\section{Should the use of polygraph be used as a measure?}

Though not perfect, it would appear to add more accurate risk assessment than simply conviction history or self-report measures. Use of polygraphy during the investigative process yields more admissions of contact victims ${ }^{22,28-31}$ and use of polygraph is essential to ascertain if the child porn offender has contact victims). ${ }^{22,28,29}$ It is estimated that likely $62 \%$ of child porn only cases would turnout to be contact offenses if polygraph is used. ${ }^{21}$ Research has demonstrated that $40-85 \%$ of child porn only offenders self-reported having undetected contact victims ${ }^{22,24,32}$ and polygraph would help in identifying those cases.

Most sexual offenses against children are vastly undetected and unreported. ${ }^{20}$ Approximately 20-25\% of investigations for child porn crimes uncover contact child sex crimes. Polygraph would help identify the child porn use with undetected victims. Understandably the cost of utilizing polygraph with every sex offender appears prohibitive at times. However, regardless of cost, failure to utilize available reliable technology is not an acceptable excuse when addressing risk concerns- especially risk concerns specific to children. Polygraph is considered state-of-the-art technology and results in far more accurate risk assessment outcomes than interview and criminal history checks alone. One last issue here. Many of the child porn, child sexual abusers, and sex offenders in general, present with traits suggestive of psychopathy. Psychopaths can easily con, fool, and manipulate others. Mental health professionals are not immune to that manipulation. It seems an issue of a lack of competence that mental health professionals ignore this fact. Polygraph is useful to combat narcissistic and psychopathic manipulation- though not perfect, far more effectively than without polygraph. In addition, testing with visual reaction time and/or plethysmography to more accurately assess and identify the offender's true sexual interest and arousal. Results from both of these technologies are warranted when assessing or treating any type of sexual offender and may result in new areas of concern for the investigator to address.

How long has the average sex offender who has minor victims been offending and how many actual victims (not just based on those known but also disclosed through the use of polygraph) does each offender have before they are arrested for the first time?

Think about those who speed or drive drunk/impaired, how many times per week or year do they speed or drive impaired before their first arrest? The reality is that most will speed or drive drunk many times before their first ticket or arrest. Studies have found that 26$85 \%$ (most average at least $50 \%$ ) of child porn offenders have multiple child contact victims that were previously undetected. ${ }^{6,21-25}$ That information proves that the offender has a lengthy history of sexually abusing children and/or others long before their arrest for child porn possession/use/production. It has been proffered that use of child porn may help some control sexual deviance while for others facilitates acting on preexisting fantasies and urges. ${ }^{33}$ However, there is no direct evidence to support the view that viewing child porn helps control deviant behavior, just opinion. Viewing deviant material may stimulate existing fantasies and lower inhibition leading to contact offenses. ${ }^{33}$ Repeated viewing of child porn and/or contact with other offenders may weaken resolve leading to contact offense. ${ }^{34}$ Remember that most sexual offenses against children are vastly undetected and unreported. ${ }^{20}$

The majority of child victim are less likely to report being victimized for 5 or more years. ${ }^{27}$ Given that most research on child porn offenders typically spans up to but less than 3 years of a known offense, this means that many victims will likely remain undetected for the period of time researchers were checking the offender's criminal history. In addition, it is often difficult to prosecute cases in which the victims were children at the time of the sexual abuse but reported the crime as late teens or adults. Victim credibility and lack of evidence and witnesses further impede a criminal conviction occurring.

For child porn cases, it is imperative to always investigate for contact offenses. Look into any contact they may have with children/ minors, any position of power/authority they may have had with minors. ${ }^{25}$ This should also include investigating the neighborhood they live in (e.g., playgrounds, churches, pools, schools) as the offender may hang around those areas watching children or engaging the children in activities. Child porn offenders with no prior sex offense convictions admitted having the most undetected victims, and their ability to remain undetected for so long requires special attention to investigate the offender's life. Of most concern is that the child porn only offender are more likely to confess to police and admit the child porn possession. They do this to lessen the chance that law enforcement would further investigate and detect that they have contact victims. ${ }^{35}$ So to the questions of how long has the offender been offending- likely years prior to any sex offense or child porn arrest. Remember that child victims are less likely to report the crime until 5 or more years later, reducing the likelihood of arrest or conviction.

\section{How is it justified that child porn offenders can continue to view and possess child porn or child porn related erotica?}

It is crystal clear that continued use of any sexually deviant material, whether child porn or child porn related erotica strengthens deviant arousal and interest- this being based on the plethora of research involving behavioral and cognitive-behavior theories, habituation theories, and learning theories.

Academic research supports the conclusion that repeated viewing of sexually deviant images, exposure to the community of other child porn or sexual offenders, and the resulting normalization of the aberrant behavior, along with the community's encouragement of sexual abuse of children, increases the risk that offenders will sexually abuse children (U.S. Department of Justice, 2010, pp. 21). This appears to also be supported by the literature examining sexual 
offense behavior. ${ }^{8-16}$ Masturbating to erotica (anything that a person finds sexually arousing) that is in any way related to a deviant sexual attraction or sexual offense behavior should be banned by use and possession by the offender. The cognitive distortions (e.g., rationalizations and excuses) offenders use to maintain their deviant sexual arousal and deviant sexual behavior help maintain the problem and may serve as permission giving to engage in sexual contact with minors. ${ }^{17}$ This suggests what I refer to as Practice and Premeditation. Practice because the offender uses the porn to strengthen deivant sexual and/or aggressive fantasies and even rehersing how to re-enact the fantasy in real-life. Premeditation because of the planning and fantasizing that occurs prior to initiating contact with the victim. This is applicable to any porn, child or adult. Research also supports that the offender's child sexual related fantasies and contact offending behavior (e.g., modus operandi) were related $\mathrm{d}^{2,23,36-30}$

Although some offenders interviewed for research studies have made the claim that viewing child pornography prevents them from engaging in contact offending, ${ }^{33}$ no empirical studies have been identified supporting those claims (as already discussed in the previous section for question 4). In fact, most of the data is based on self-report by the offender and the offender having no criminal conviction involving sexual contact with children/minors. That does not in any way suggest that the child porn only offender has no contact victims, just that the possible victims are yet undetected. In addition, there is no empirical support to identify with any degree of accuracy at what point a child porn only offender would engage in contact sexual contact with a child or teen.

One of the main problems in allowing the child porn offender to view any type of porn or eroctica is that it further strengthens the offender's belief that they are not causing the depicted child har, and that their behavior is in some way appropriate. The children depicted in the porn did not display signs of resistance or harm or may have appeared to enjoy the sexual contact, and the child is not believed to be harmed by the sexual contact or that in some way the child enojys the sexual contact being depicted. ${ }^{15,17,40-45}$ This allows for the offender to strengthen their sexual beleifs involving children. This may help maintain a sense of sense of entitlement to engage children or adolescents in sexual activities. ${ }^{42}$

Continued use of child porn material further strengthens deviant sexual and aggressive beliefs and behavior and it is highly likely that the porn material will become increasingly more deviant and violent in nature. The NDIC (National Drug Intelligence Center) found that 82 percent of respondents reported victims (all of whom were minors) in all age brackets, many including infants. Also, according to the NDIC interviewees, 63 percent of respondents reported increased violence toward child pornography victims, 42 percent more bondage, 38 percent more sadism and masochism, and 15 percent more bestiality. Although 21 percent reported no change in violence, no respondents reported decreased violence. This suggests that with continued porn use (would likely include use of erotica as well), the child porn offender may actually become attracted to/desensitized to increasingly more aggressive and deviant porn which in tern may lead to the offender's decision to engage in contact offending and more extreme contact offending.

There is a direct correlation between the theme of collected porn of any type and criminal behavior. Remember that practice makes perfect- collecting, viewing, and masturbating to deviant porn strengthens deviant thinking which almost always will lead to deviant behavior at some point. The content of the child porn/erotica and the offender's behavior in the contact offense were similar in theme..$^{21,46}$ Research also supports that the offender's child sexual related fantasies and contact offending behavior (e.g., modus operandi) were related. $2,23,33,36,37,39$ One could argue that continued strengthening of deviant sexual interests in minors increases risk for some to perpetrate contact sex crimes against minors- whether it be within a year or more, difficult to assess accurately. Research that fails to involve polygraphy and long-term follow-up (ten plus years at risk) likely minimizes the true cross-over rate. We simply do not often have data that reflects the above concerns, rather relying on offender self-report. It may not matter whether the offender began viewing child porn prior to or subsequent to contact offending- most of that data is based on self-report with no polygraph verification. Practice makes perfect and at some point, given what we understand of behavioral practice, learning theory and habituation, the offender is at increased risk for engaging in touch offenses.

Many of the child porn offenders view themselves as being unable to control their urges or behaviors, beleiving that they are unable to stop themselves and this has been referred to in the literature as external locus of control. This suggests that the child porn offender dmeonstrate characteristics of impulse control or feelings of addiction to the Internet and therefore believing that they are out-of-control. ${ }^{47-51}$ However, there is no proof, no evidence to support their actually being out-of-control.

\section{Allowing for the use of child porn material increases the need for more child porn material to be made. The use of child porn is not a victimless crime}

It is theorized that because of the unlimited supply of free child porn and other deviant sexual material online that many offenders can view material they may or may not have ever seen, some of which may be novel to the offender. With repeated use/viewing of the material, the viewer becomes desensitized and believes that there is nothing wrong with viewing and perhaps eventually acting-out what is portrayed in the online material..$^{52}$ This suggests that through continued use of child porn material or child erotica of any type may introduce new ideas of sexual contact with children, which in turn increases the likelihood of the child porn only offender moving to actual contact offenses. In addition, the more porn is used, the more demand for new porn is created. ${ }^{53-57}$ This is true of anything, the more of a demand, the more of similar material required to appease a consumer base. Now include homemade child porn or any homemade porn that is uploaded and shared, there is always new porn available. Once a victim's photos or video is shared online, it is nearly impossible to have it removed from a porn site. In addition, once on one porn site, the photos will likely be on over a hundred-thousand porn sites, making continued victimization of the victim a nightmare.

"This growing and thriving market for child pornographic images is responsible for fresh child sexual abuse-because the high demand for child pornography drives some individuals to sexually abuse children and some to "commission" the abuse for profit or status" (U.S. Department of Justice, August 2010, pp. 17).

Children and adolescents involved in the child porn industry are victimized in ways that many may not clearly understand. "Unlike children who suffer from abuse without the production of images of that abuse, these children struggle to find closure and may be more prone to feelings of helplessness and lack of control, given that the 
images cannot be retrieved and are available for others to see in perpetuity. They experience anxiety as a result of the perpetual fear of humiliation that they will be recognized from the images" (U.S. Department of Justice, August 2010, pp. 9).

A high percentage of children sexually abused likely never report the sexual contact or may not do so until they are much older, reducing the likelihood of prosecution due to the time lapse. ${ }^{27}$ The offender may use threats, intimidation, blackmail, bribes, gifts, seduction, and competition to gain victim compliance and secrecy, ${ }^{58,59}$ which also makes it more likely that the child victim will delay any reporting of the sexual abuse. Always ask victims if the offender took pictures of them. If so, find the pictures and what was used to take the pictures or videos (cell phoone, camera). The sexual behavior of the child is almost always recorded by the offender for sexual gratification and may also be used to blackmail and threaten the child into continued submission and compliance and secrecy. ${ }^{60-64}$

\section{Are the researchers and sex offender treatment professionals thereby condoning and minimizing child porn material/child related erotica?}

If viewing child porn and related erotica is a serious problem and concern, then there should be no disagreement that any use of child porn or child related erotica is wrong and off limits. The percentage of child porn users who engage in contact offenses is high- around $50-85 \%$ as previously mentioned. Even $50 \%$ is high because it represents child and adolescent victims. For child porn offenders or any offenders to be allowed to view child porn or child related erotica is simply wrong. Continuing to strengthen deviant sexual arousal does not help prevent sex crimes but further increases the risk for sex crimes (as previously discussed throughout this article). The child porn user victimizes the children and adolescents victimized in the porn industry. The continued use of child porn and child related erotica further victimizes children and again increases the risk for contact offenses.

Wow, have we really come to this point? Is the victimization of children not enough to make child porn/child related erotica disturbing and illegal? Oh wait, it is both! The users of child porn/child related erotica are supporting, directly supporting the manufacturing of child porn and child related erotica- thereby actively involved in the problem. The problem is the physical and sexual victimization of minors. Engaging in the use of such material should be appalling enough to warrant years in prison for the first offense. How many thousands of children need to be sexually abused because it is no big deal to view child porn or child related erotica? In addition, the users of child porn/child related erotica are directly responsible for the need for more and more production of such materials and most, not some, will sexually abuse, molest, rape children.

It is concerning that there is a lack of empirical evidence to support any claim made by child porn users and child molesters that continued use of child porn/child erotica helps prevent them from engaging in actual or subsequent contact sexual offenses. Yet researchers continue to proffer that the claims made by offenders of not having contact victims or not having urges to sexually offend with contact victims is somehow supported by the literature when in fact it is not. The literature continues to falsely and knowingly misuse the data to support that child porn offenders present with low risk for committing contact sex offenses and that they have no contact victims- that is what the majority of the research states- all based on child porn offenders self-report, but lacking any objective scientific support such as polygraph data. Asking offenders to self-report whether they have undetected contact victims or whether they have increasingly stronger and more deviant sexual fantasies as a result of continued use of child porn/child related erotica is absurd. The only thing the literature offers as support is that the offenders themselves deny having any contact victims (though not polygraphed) and the lack of any sex related convictions- again, however, 26-85 (again, on average 50\% or higher) admit to having undetected contact victims.

The child porn offender is allowed in many states to purchase and masturbate to boys/girls underwear (erotica) as well as to clothed pictures of children. This only serves to strengthen deviant sexual arousal yet somehow is legal for the offender to do. Unfortunately, some sex offender treatment professionals concur with this practice. There appears to be empirical support that continued use of the deviant materials (e.g., porn, erotica) strengthens deviant cognitions and beliefs and makes it more likely that the offender will engage in contact sexual offenses. Lastly, nearly $80-90 \%$ of child porn only offenders continued to offend (use child porn) while in treatment and after treatment. ${ }^{65,66}$ So, most child porn offenders choose to keep viewing child porn material/child related erotica while in treatmentwhat is treatment doing that is effective for the child porn offender? And again, that sex offender treatment professionals may allow the child porn offender to continue using and masturbating to child related erotica does not make any sense- in fact defies logic. That would be the same as telling the alcoholic that they should keep a bottle of booze handy to look at and smell-eventually they will drink it. Treatment becomes an accomplice to child sexual abuse and those children involved in the child porn industry are further imprisoned by the condoning of such behavior.

\section{Conclusion}

The sex offender field tends to misrepresent data related to the child porn offender. Based on flawed research, the child porn offender is deemed to pose a low risk for engaging in any future contact sexual offense behavior. This, based on the offender's self-report and a lack of any sexual criminal history. Research demonstrated that some sexual offenders in fact have minimal if any criminal history and many that do have a criminal history may have related offenses but not direct sex offense convictions. ${ }^{67,68}$

There is empirical support for the following. The majority of child porn offenders have undetected contact victims, undetected sex crime offenses, and continue to offend with use of child porn/child related erotica even while in sex offender treatment. Continued use of child porn material/child related erotica strengthens deviant thinking, helps to further strengthen justification for continued use of such material, and is likely to lead to the justification of contact offense behavior.

The follow-up period for any sex offender is far too short, averaging 3 years or less. This assumes that the offender will be arrested and convicted immediately of any subsequent offense, despite that fact that most offended for years before getting arrested for the first time. The follow-up period for recidivism need to be 25 plus years. In addition, use of polygraph should be protocol for any risk assessment and for any research that portrays to assess the risk of sex offenders/ child porn offenders for recidivism and for any type of contact offense. Nuisance sex offenses (e.g., exhibitionism, voyeurism) need to be taken serious as part of the offender's pathology and related to any future sex offending or assault behavior. Research that fails to 
use polygraph and fails to look 20 or more years out seems at best useless. These studies have serious flaws and limitations in their overall predictability of future sex and violent offenses and mislead the public about the offender's degree of safety risk.

I believe that this paper represents important and urgent concerns that need to be addressed. This paper should serve as a discussion to address the above concerns and help strengthen out field.

\section{Acknowledgments}

None.

\section{Conflicts of interest}

Author declares that there is no conflict of interest.

\section{References}

1. Hazelwood RR, Lanning KV. Collateral materials in sexual crimes. In: Hazelwood RR, Burgess AW, editors. Practical Aspects of Rape Investigation: A Multidisciplinary Approach. Boca Raton, Florida: CRC Press Inc; 1995.

2. Lanning KV. Cyber "pedophiles": A behavioral perspective. In: RR Hazelwood, AW Burgess, editors. Practical aspects of rape investigation: a multidisciplinary approach $4^{\text {th }}$ ed. Boca Raton, FL: CRC Press; 2009. p. $381-407$.

3. Johnson SA. Erotica and the sexual offender: The importance of restricting sex offenders from using or possessing erotica and pornography. Forensic Research \& Criminology International Journal. 2018;6(2):00186.

4. Johnson SA. Child porn offenders, solicitation offenders and child sexual abusers: What the literature has to say. Forensic Research Criminology International Journal. 2019;7(4):202-235.

5. Armagh DS. Virtual child pornography: Criminal conduct or protected speech. Cardozo Law Review. 2002;23:101-117.

6. Wolak J, Finkelhor D, Mitchell K. Child pornography possessors arrested in Internet-related crimes: Findings From the National Juvenile Online Victimization Study. Alexandria, VA: National Center for Missing \& Exploited Children; 2005.

7. US. Department of Justice. The National Strategy for Child Exploitation Prevention and Interdiction: A REPORT TO CONGRESS. 2010.

8. G G Abel, J V Becker, J Cunningham-Rathner. Complications, consent, and cognitions in sex between children and adults. International Journal of Law and Psychiatry. 1984;7(1):89-103.

9. Bumby KM. Assessing the cognitive distortions of child molesters and rapists: Development and validation of the MOLEST and RAPE scales. Sexual Abuse: A Journal of Research and Treatment. 1996;8(1):37-54.

10. Burns DD. The feeling good handbook. New York, NY: William Morrow and Co. 1989.

11. Leslie Helmus, R Karl Hanson, Kelly M Babchishin, et al. Attitudes supportive of sexual offending predict recidivism: A meta-analysis. Trauma, Violence \& Abuse. 2013;14(1):34-53.

12. Mann RE, Marshall WL. Advances in the Treatment of Adult Incarcerated Sex Offenders. In: AR Beech, LA Craig, KD Browne, editors. Assessment and treatment of sex offenders: A handbook. West Sussex: John Wiley \& Sons; 2009. p. 329-347.

13. Neidigh L, Krop H. Cognitive distortions among child sexual offenders. Journal of Sex Education \& Therapy. 1992;18:208-215.

14. Ciardha C, Gannon TA. The cognitive distortions of child molesters are in need of treatment. Journal of Sexual Aggression. 2011;17(2):130-141.
15. Caoilte O Ciardha, Tony Ward. Theories of cognitive distortions in sexual offending: What the current research tells us. Trauma, Violence, \& Abuse. 2013;14(1):5-21.

16. Pollack NL, Hashmall JM. The excuses of child molesters. Behavioral Sciences \& the Law. 1991;9:53-59.

17. Kettleborough DG, Meridan HL. Gateway to offending behavior: Permission-giving thoughts of online users of child sexual exploitation material. Journal of Sexual Aggression. 2017;23(1):19-32.

18. US. Postal Inspection Service (USPIS). As cited in U.S. Department of Justice. The National Strategy for Child Exploitation Prevention and Interdiction: A Report to Congress. 2010. p. d29.

19. Neutze J, Seto M, Schaefer GA, et al. Predictors of child pornography offenses and child sexual abuse in a community of pedophiles and hebephiles. Sexual Abuse: A Journal of Research and Treatment. 2011;23:212-242.

20. Lussier P, Cale J. Beyond sexual recidivism: A review of the sexual criminal career parameters of adult sex offenders. Aggression and Violent Behavior. 2013;18(5):445-457.

21. Owens JN, Eakin JD, Hoffer T, et al. Investigative aspects of crossover offending from a sample of FBI online child sexual exploitation cases. Aggression and Violent Behavior. 2016;30:3-14.

22. Bourke ML, Hernandez AE. The "Butner Study" redux: A report of the incidence of hands-on child victimization by child pornography offenders. Journal of Family Violence. 2009;24:183-191.

23. Lanning KV. Child molesters: A behavioral analysis. For Professionals Investigating the Sexual Exploitation of Children. National Center for Missing \& Exploited Children. Office of Juvenile Justice and Delinquency Prevention. 2010.

24. Michael C Seto, R Karl Hanson, Kelly M Babchishin. Contact sexual offending by men with online sexual offenses. Sexual Abuse: A Journal of Research and Treatment. 2011;23:124-145.

25. Shelton J, Eakin J, Hoffer T, et al. Online child sexual exploitation: An investigative analysis of offender characteristics and offending behavior. Aggression and Violent Behavior. 2016;30:15-23.

26. McCarthy J. Internet sexual activity: A comparison between contact and non-contact child pornography offenders. Journal of Sexual Aggression. 2010;16:181-195.

27. D W Smith 1, E J Letourneau, B E Saunders, et al. Delay of disclosure in childhood rape: Results from a national survey. Child Abuse and Neglect. 2000;24:273-287.

28. Bourke ML, Fragomeli L, Detar PJ, et al. The use of tactical polygraph with sex offenders, Journal of Sexual Aggression. 2015;21(3):354-367.

29. Buschman J, Wilcox D, Krapohl D, et al. Cyber sex offender risk assessment. An explorative study. Journal of Sexual Aggression. 2010;16:197-209.

30. Heil P, English K. Sex offender polygraph testing in the United States: Trends and controversies. In DT Wilcox, editor. The use of polygraph in assessing, treating and supervising sex offenders: A practitioners'guide. United Kingdom: Wiley-Blackwell; 2009. p. 181-216.

31. Gannon TA, Hoare JA, Rose MR, et al. A re-examination of female child molesters' implicit theories: evidence of female specificity? Psychology Crime \& Law. 2009;18(2):209-224.

32. Merdian HL, Moghaddam N, Boer DP, et al. Fantasy-driven versus contact-driven users of child sexual exploitation material: Offender classification and implications for their risk assessment. Sexual Abuse. 2018;30(3):230-253. 
33. Quayle E, Taylor M. Child pornography and the internet: Perpetuating a cycle ofabuse. Deviant Behavior: An Interdisciplinary Journal. 2002;23:331-361.

34. Houtepen JABM, Sijtsema JJ, Bogaerts S. From child pornography to child sexual abuse: A review of child pornography offender characteristics and risks for cross-over. Aggression and Violent Behavior. 2014;19:466-473.

35. McManus MA, Long ML, Alison L, et al. Factors associated with contact child sexual abuse in a sample of indecent image offenders. Journal of Sexual Aggression. 2015;21(3):368-384.

36. Dandescu A, Wolfe R. Considerations on fantasy use by child molesters and exhibitionists. Sexual Abuse: A Journal of Research and Treatment. 2003;15(4):297-305.

37. Marshall WL, Barbaree HE, Eccles A. Early onset and deviant sexuality in child molesters. Journal of Interpersonal Violence. 1991;6:323-336.

38. Quayle E, Taylor M. Model of problematic internet use in people with a sexual interest in children. Cyber Psychology \& Behavior. 2003;6:93-106.

39. Warren J, Hazelwood R, Dietz P. The sexually sadistic serial killer. Journal of Forensic Sciences. 1996;41:970-974.

40. Howitt $\mathrm{K}$. The role of cognitive distortions in paedophilic offending: Internet and contact offenders compared. Psychology, Crime \& Law. 2007;13:469-486.

41. Marziano V, Ward T, Beech AR, et al. Identification of five fundamental implicit theories underlying cognitive distortions in child abusers: A preliminary study. Psychology, Crime \& Law. 2006;12(1):97-105.

42. Ward T, Keenan T. Child molesters' implicit theories. Journal of Interpersonal Violence. 1999;14:821-838.

43. Webster S, Davidson J, Bifulco A, et al. Final report. European Online Grooming Project. 2012.

44. Winder B, Gough B. I never touched anybody - that's my defence": A qualitative analysis of internet sex offender accounts. Journal of Sexual Aggression. 2010;16(2):125-141.

45. Ward T. Sexual offenders' cognitive distortions as implicit theories. Aggression and Violent Behavior. 2000;5(5):491-507.

46. Hoffler T, Muirhead Y, Owens J, eta al. Like a puppet on a string: Understanding grooming behaviors of child sex offenders. Crimes Against Children: Behavioral and investigative perspectives from the FBI's behavioral analysis unit. Washington, DC: Department of Justice (FBI). 2015.

47. Bates A, Metcalf C. A psychometric comparison of Internet and nonInternet sex offenders from a community treatment sample. Journal of Sexual Aggression. 2007;13:11-20.

48. Elliot IA. Psychological characteristics of users of child pornography on the internet. Doctoral dissertation. 2012

49. Elliott IA, Beech AR., Mandeville-Norden R, et al. Psychological profiles of internet sexual offenders: Comparisons with contact sexual offenders. Sexual Abuse: A Journal of Research and Treatment. 2009;21(1):76-92.

50. Gannon TA, Wood JL, Pina A, et al. An evaluation of mandatory polygraph testing for sexual offenders in the United Kingdom. Sexual Abuse. 2013;26(2):178-203.

51. Polaschek DLL, Calvert SW, Gannon TA. Linking violent thinking: Implicit theory-based research with violent offenders. Journal of Interpersonal Violence. 2009;24(1):75-96.
52. Burgess AW, Marchetti CH. Contemporary issues. In: RR Hazelwood, editor. 2009.

53. Russell DEH. Pornography and Violence: What does the new research say? In: L Lenderer, editor. Take Back the Night: Women on Pornography. New York: Morrow, 1980. In Zillman, D., \& Bryant, J. Pornography, sexual callousness, and the trivialization of rape. Journal of Communication (pre-1986): Autumn 1982; 32, 4.

54. Russell DEH. Making Pornography Sexy: Feminist views on pornography. NewYork: Teachers College Press, 1993, and Buckingham, England: Open University Press; 1993.

55. Russell DEH. Against Pornography: The evidence of harm. Berkeley, California: Russell Publications; 1994.

56. Russell DEH. Dangerous Relationships: Pornography, misogyny, and rape. NewburyPark, California: Sage Publications, 1998. Revised, expanded edition of Against Pornography: The evidence of harm. Berkeley, California: Russell Publications, 1994.

57. Russell DH. Against Pornography: The evidence of Harm. Presentation at the Association for the Treatment of Sexual Abusers, 18th Annual Research \& Treatment Conference. Orlando, Florida. 1999. p. 22-25.

58. Campbell AM. False faces and broken lives: An exploratory study of the interaction behaviors used by male sex offenders in relating to victims. Journal of Language and Social Psychology. 2009;28:428-440.

59. Sullivan J, Quayle E. Manipulation styles of abusers who work with children. In: M Erooga, editor. Creating safer organisations: Practical steps to prevent the abuse of children by those working with them. Chichester, UK: John Wiley; 2012. p. 85-98.

60. Briggs P, Simon WT, Simonsen S. An exploratory study of Internet initiated sexual offenses and the chat room sex offender: Has the Internet enabled a new typology of sex offender? Sexual Abuse. 2011;23:72-91.

61. Grosskopf A. Online interactions involving suspected paedophiles who engage male children. Trends and Issues in Crime and Criminal Justice. 2010;403:1-6.

62. Krone T. Queensland police stings in online chat rooms. Trends \& Issues in Crime and Criminal Justice. 2005;301:1-6.

63. Mitchell KJ, Finkelhor D, Wolak J. Youth internet users at risk for the most serious online sexual solicitations. American Journal of Preventive Medicine. 2007;32:532-537.

64. O'Connell R. A typology of cyber sexploitation and online grooming practices. Cyberspace Research Unit University of Central Lancashire. 2003.

65. Klaus M Beier, Dorit Grundmann, Laura F Kuhle, et al. The German Dunkelfeld Project: A pilot study to prevent child sexual abuse and the use of child abusive images. The Journal of Sexual Medicine. 2015;12(2):529-542.

66. Kuhle LF, Neutze J, Amelung D, et al. Treatment-change in child pornography offending in pedophiles and hebephiles in the Prevention Project Dunkelfeld. Paper presented at the conference of the International Association for the Treatment of Sexual Offenders. Germany: Berlin. 2012.

67. Grubin D. Sex offending against children: Understanding the risk. Police research series paper 99. London: Home Office; 1998.

68. Winder B, Gough B, Seymour-Smith S. Stumbling into sexual crime: The passive perpetrator in accounts by male internet sex offenders. Archives of Sexual Behavior. 2015;44(1):167-180. 